\title{
Bio-Design Intelligence
}

\author{
Ana $\operatorname{Zimbarg}(\bowtie)$ \\ Florida International University, 11200 SW 8th Street, Miami, FL 33199, USA \\ azimb003@fiu.edu
}

\begin{abstract}
Architecture has a substantial influence worldwide as it shapes our cities, and it is made to last. Urban areas are also responsible for $70 \%$ of the world's carbon emissions. Consequently, architects are responsible for minimising the destructive effects of construction on the environment. How can biological intelligence be inserted in architecture as a possibility to increase environmental performance? Bio-design goes further than biology-inspired approaches. Biodesign refers to incorporating living organisms as an essential component of a system, changing the natural and built environment boundaries. It contains living and machine intelligence, whether embedded in the design process or in the building itself. This paper seeks to give an overview of bio-design and how it can be seen as a strategy of thinking of new research pathways.
\end{abstract}

Keywords: Bio-design $\cdot$ Hybrid architecture $\cdot$ Biodigital

\section{Introduction}

Architecture has an extensive presence in the world. It is made to last a long time and impacts various scales in the urban context as well as the natural environment. Since 2007, more than $50 \%$ world's population has been living in cities, and it is expected to rise to $60 \%$ by 2030 . Urban areas are also responsible for $70 \%$ of the world's carbon emissions (Cities - United Nations Sustainable Development 2021). Consequently, architects are responsible for minimising the destructive effects of construction on the environment.

Current technology and easy access to other disciplines such as biology and computation can greatly value developing an architecture that can simultaneously benefit humans and the environment. Cities are designed following a linear organisation, meaning that the resources come from one side, producing waste that leaves the system on the other side; this model adds strain into the biosphere, pushing some of the ecosystems outside of a healthy balance. However, the planet does not function following a linear model; it works as a nonlinear, complex dynamic system with millions of interactions that support life (Poletto 2018). Thus, using design embedded with microorganisms can play a part in creating a circular urban metabolism.

It is necessary to clarify that the work discussed in this paper is not about biomimetics but about embedding bio-intelligence within architecture to expand the space of solutions to given problems. In essence, biomimetics uses biological entities and processes to shape design and the production of materials, structures, and systems. Although mimicry 
may be a productive methodology, it implies incorporating nature into existing methods (Rigobello 2019). At one point in the process, biomimetics has an abstraction and detachment element from the biological model to achieve its goals (Primrose 2020).

Therefore, how biological intelligence can be inserted in architecture as a possibility to increase environmental performance? Bio-design goes further than biology-inspired approaches; Bio-design refers to incorporating living organisms as an essential component of a system modifying the boundaries between natural and built environment (Myers 2018). Additionally, bio-design scaffolds on computational and synthetic biology and it is applied through material driven design, interactive systems, or a combination of both (Gough et al. 2020). This paper seeks to give an overview of how biology can be incorporated into design through a brief analysis of recent projects and research and how bio-design can play a part in straightening relationships between humans and the natural world.

\section{Natural Intelligence}

The second half of the twentieth century was marked by great biological discoveries such as Charles Darwin and Alfred Wallace's evolution theories, signifying an enormous change in paradigm and understanding of the planet's dynamics. These discoveries influenced other disciplines. The impact of biology in architecture appears in the form of biomorphism (Melkozernov and Sorensen 2020), as seen in Antoni Gaudi work and Frei Otto's light structures.

Frei Otto's theoretical and experimental investigation of multiple objects of different nature has an extensive impact on the field of architecture, engineering, and design. Otto's work references many developments in current building design and scientific research, including architecture, engineering, and biology. His idea of not using bionics but looking and understanding nature itself for technical or architectural applications (Burkhardt 2016; Aldinger 2016) plays an integral part in combining other disciplines in the making of architecture. Frei Otto's ability to use physical models as design tools for form-finding contributed immensely to embedding natural laws into architecture. In a way, Frei Otto inserted nature in his work; the lightweight tensile structures, have within their materiality, the bubble properties used to experiment surface tension (Figs. 1).
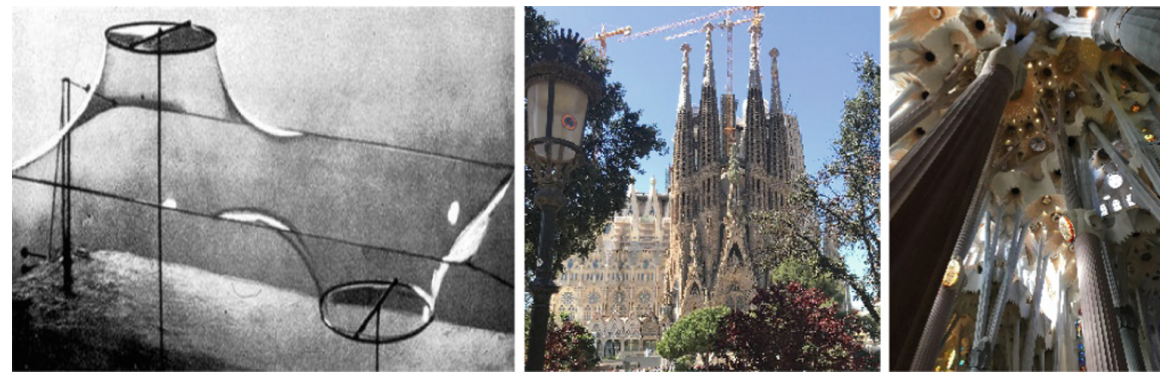

Fig. 1. Left: Frei Otto experiment with soap bubble (Zexin and Mei 2017) Centre and Right: La Sagrada Familia, Barcelona, Spain (images by author 2018) 
The idea of bringing nature into design is now possible with technological advances. Claudia Pasquero proposes that architects should recognise that architecture, instead of taking from, should provide to other disciplines, contributing to their realisation (Pasquero and Poletto 2020). Pasquero's work uses architecture as a meta-language to communicate with the non-human by developing systems embedded with biomaterial. Additionally, Marco Poletto points out that our society has established the idea that bacteria and microorganisms are dangerous and should be removed from the urban environment (Poletto 2018). Excluding other species from urban spaces is questioned, motivated by a frantic race for sustainable solutions to stop environmental changes. Although it is unlikely that humankind will find a solution for all the consequences of temperature rise, these problems push and open new research fields.

The current urban setup primarily relies on energy, consequently responsible for the extreme amount of carbon dioxide emissions into the atmosphere. The fourth U.S. National Climate Assessment (NCA4) has stated strong evidence that these changes are highly likely to result from human activities (Wuebbles et al. 2017). Climate change leads architects and designers to think of solutions to reduce the human impact on the environment and reduce the speed of the effects that greenhouse gases have in the biosphere.

Research on algae has been increasing within the architectural community to reduce the consequences of the Anthropocene age. Contemplating embedding living organisms in buildings can often be perceived as a science fiction idea; however, this technology is becoming more accessible and feasible. There are initiatives from the government and companies. "VIDA_BIOCAS, a Bio Self-Sufficient City from algae" is a proposal developed by a consortium of companies specialised in energy along with a partnership with the Spanish government that targets to combine life with lifeless. Integrating algae with technologies and materials capable of conducting liquids, along with microalgae, $\mathrm{CO}^{2}$ and nutrients that can be converted through photosynthesis, could be a possibility to reduce the pressure that energy production has in the environment. Such projects can use bio-reactors ${ }^{1}$ integrated into buildings surfaces (Pacheco-Torgal et al. 2021). VIDA_BIOCAS tries to find a system applicable on different scales (from building facades to street furniture).

The significance of such commercial projects is that it illustrates that companies and the government are considering hybrid design ${ }^{2}$ as a possible solution, which could encourage designers to develop more sophisticated use and techniques of integrating natural intelligence in architecture.

\footnotetext{
${ }^{1}$ Bioreactors are piping systems with water, algae, nutrients, and carbon dioxide inside. These pipes are clear to allow for the algae to effectively capture sunlight to process and convert inorganic matter into sugar. The biomass produced can be valuable to humans (Pacheco-Torgal et al. 2021).

${ }^{2}$ Hybrid Design is referring to the fusion of technology and living organisms and its relationships as components of a design/ architecture system or structure.
} 


\subsection{BioHybrids}

The application of a hybrid system to construction is relevant, as automation in architecture is growing in popularity, and biological organisms are highly efficient in producing material with limited resources; therefore, investigating biohybrid robotics can be perceived as an emerging trend (Heinrich et al. 2019).

The majority of existing biohybrid construction combines biological organisms with manual manipulation. It is done with mechanical elements, and there is research on how to reduce human interference in the maintenance of the systems and increase automation. Projects such as Claudia Pasquero and Marco Poletto's "BioTechHUT" involve a structure supporting the organisms that live within its interior. There is a symbiotic relationship between the user and algae. The user nourishes the environment with carbon dioxide, and the symbiosis between bacteria and algae collect gases to produce oxygen, biomass, and electricity. The researchers developed the system to be integrated within the building's skin; this system produces $1 \mathrm{~kg}$ of algae per day, meaning that it can release $10 \mathrm{~kW} / \mathrm{h}$ of energy, which is what an average U.K. home needs to power its system (Poletto 2018) (Fig. 2).

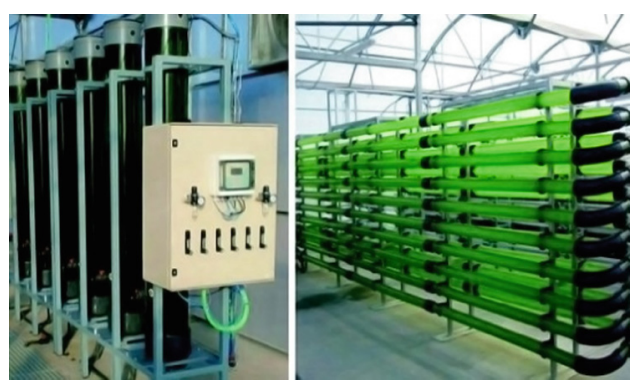

Fig. 2. Industrial microalgae photo-bioreactors, Alga Energy company installations (Provided by Alga Energy in Pacheco-Torgal et al. 2021)

A step further would be taking the biohybrid concept more literally and applying it used to produce intelligent material. Material intelligence, in this case, refers not only to the material performance but also to the intelligence used in the material design process. Developing building components from living material such as cellulose shaped into membranes produced by bacteria to create intelligent materials such as translucent membranes illustrate this concept.

This partnership between technology and nature touches the realms of creating symbiotic $^{3}$ relationships between robots and living organisms endeavouring to produce architecture. Claudia Colmo's "Restless Labyrinth" is research on producing growing

${ }^{3}$ In biology, symbiosis identifies a continuing relationship between two or more species with different associations: mutualism, where the interaction between species benefits both sides; commercialism, where the interaction benefits only one species but does not injure the other and parasitism where one species benefits while the other is harmed (Šijaković and Perić 2018) sija. The most fundamental symbiotic relationship is animals eating plants and animal physiological wastes becoming fertiliser for plants. This relationship between species is most important for 
architecture targeting achieve technological breakthroughs such as growing mycelium composites at building scale and manipulating the mycelium network to act like a computationally active material (Rigobello 2019).

Colmo's research contributes to expanding a research field that explores a symbiotic relationship between human and other species by using biology to produce structures to remediate contaminated sites. The fabrication and growth of these structures have been investigated through experiments aiming to find compostable material compatible with 3D printing. The researcher's findings have proven robust, biocompatible, and symbiotic with the tested organism. The research will increase the scale by implementing lignocellulosic substrates within a 3D printed soil-based composite (Colmo and Ayres 2020) (Fig. 3).

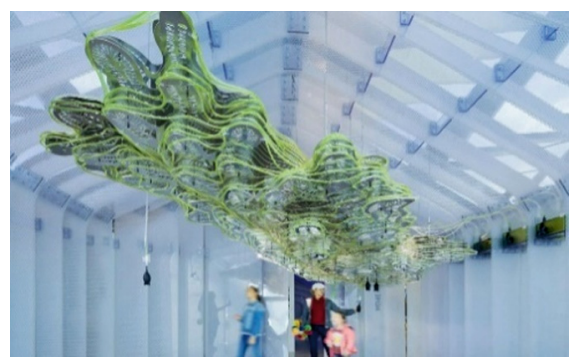

Fig. 3. BioTech HUT (Photography by NAARO in (Poletto 2017)

"Restless Labyrinth" is successful concerning its material composition as they present themselves as robust, biocompatible, and symbiotic with the introduced organisms. Nevertheless, incorporating living organisms into an artificial system is a slow and challenging process. The project's limitations lie in fabrication. The research demonstrated that there are still many issues to resolve related to scale.

William Myers said that the demand for different design solutions, more integrated with the natural world, is growing and accelerating interdisciplinary collaborations (Myers 2018). The presented projects exemplify many solutions to incorporating biological elements within an architectural structure and creating symbiotic relationships between humans, non-human and machines.

Our settlement practices generally do not consider the impact on local ecosystems. Ecosystems and their services are not limited to borders (Sachs 2015 in: Joachim and Gervasi 2020). The design approach used to develop urban organisation ignores existing natural processes and species, indicating that we are executing poor treatment of the surrounding environment. As a consequence of human settlement and spread, invasive species naturalise in areas causing a negative impact on the original ecosystem (Joachim and Gervasi 2020).

Embedding design with natural intelligence does not mean that living organisms are necessarily part of an architectural system. More importantly, it may be perceived to

most species' survival (Frederick 2015). The symbiotic relationship referred in this paper is a mutualistic relationship between the parts invoveld. 
include the natural world in the design process instead. Mitchell Joachim and Nicholas Gervasi point out that "our treatment of plants and animals reflects our society's values". Moreover, they reflect human settlement behaviour, where humans choose a specific region to settle where resources can be exploited and converted into economic gains resulting in the decline of the non-human sector.

The concept of smart cities began to emerge about ten years ago, introducing the Internet of Things idea into the urban scale. We now understand better the potential of digital technologies and how artificial intelligence can manage cities. Digital technology has the potential to allow the planning and construction of cities as natural ecosystems (Guallart 2020).

Machine intelligence is an essential component in bio-design, whether it is embedded in the product or the design process. Introducing life into architectural systems can use digital and robotics technology to simulate, predict, and control (through complex mathematical equations) these biological systems (Marcos Cruz 2017). Pasquero and Poletto (founders of EcoLogic Studio) are working on new urban planning strategies called Deep Green - to contribute to waste management, water conservation, recycling, and energetic circularity. There must be a shift in the perception of the urban space to achieve these ambitions, which these two researchers approached by designing the city as a refuge for humans and wildlife. United Nations Development Programme and EcoLogic Studio are testing artificial intelligence's potential to develop a new green planning interface using algorithms to analyse high-resolution data on urban landscape and infrastructure to simulate possible sustainable urban scenarios development (Pasquero and Poletto 2020).

By integrating other species into the design process, a connection between humans and wildlife (in the case of Deep Green) is generated through artificial intelligence, demonstrating the wide variety of solutions that can be achieved with bio-design. Such initiatives could generate new relationships with other species resulting in more sustainable and resilient cities.

\section{Bio-Material Intelligence}

As Mark Weiser said, "The most profound technologies are those that disappear", meaning that they become part of everyday life until they are not visible (Pataranutaporn et al. 2020). Human settlement turns other species 'invisible'. Being aware of this invisibility may open paths to integrate and recreate relationships between human-made and the unseen, resulting in a 'healthier' invisibility.

Biological processes are considered alternatives to traditional technologies to achieve material and energy-saving and reduce carbon footprint. CiTG from the Delft University of Technology in the Netherlands is developing bio concrete. A specialised bacterium (extremophiles ${ }^{4}$ ) is inserted into the concrete where these bacterias can thrive and naturally produce limestone. This technique is beneficial to reduce the carbon emission in the production of concrete, as the limestone burned in the process, producing calcium oxide, releases significant quantities of carbon dioxide into the atmosphere (Myers 2018).

$\overline{{ }^{4} \text { Extremophiles }}$ are resilient and can survive in harsh conditions (González, Keller and Joachim no date). 
Further research in this field found that bacterial spores and calcium lactate when inserted in the concrete. For years, the spores lay dormant until water ingress within the concrete structure throughout time. Humidity triggers the bacteria to produce $\mathrm{CO}^{2}$. In concrete's highly alkaline environment, this $\mathrm{CO}^{2}$ combines with calcium ions to form solid calcium carbonate, which can seal cracks up to one millimetre wide, preventing further water damage (Mark Peplow 2020) (Fig. 4).

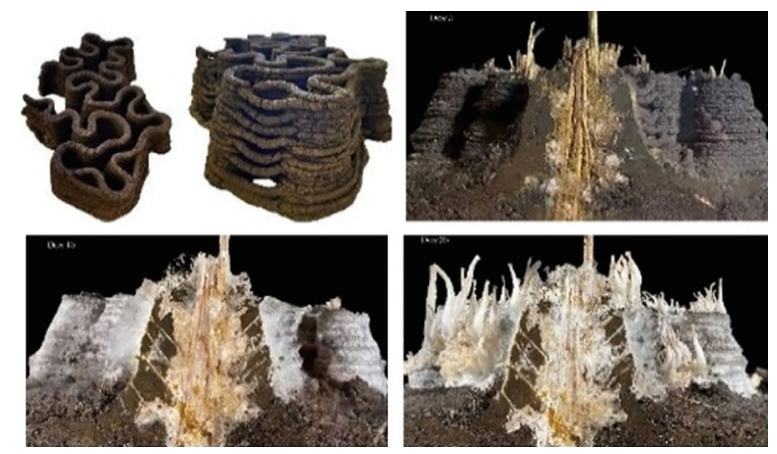

Fig. 4. Configuration of the $3 \mathrm{~d}$ printed single skin prototype before inoculation and transfer to incubation tank(top) and time-lapse of mycelium colonisation over35 days (Colmo and Ayres 2020)

Many types of bacteria have been documented by biologists, with innumerous features. Vibrio Fischeri is a bacterium that has bioluminescent properties. Its bioluminescence is caused by quorum sensing ${ }^{5}$. Therefore, to show the bioluminescent properties, the bacteria need to have their population density high enough to allow cell interactions to induce the enzymes necessary for the bacteria to glow. Vibrio Fischeri populations get the nutrients from a symbiotic relationship with animals. In exchange, it helps animals to find mates, ward off predators, attract preys or communicate with other organisms due to its bioluminescent properties (González, Keller and Joachim, no date). Eduardo Mayoral González performed a series of tests to check their glowing properties and investigate possibilities of using these bacteria to illuminate natural environments, commercial billboards, signposting, or ambient lighting (Fig. 5).

Incorporating living elements in material generates another form of intelligent material, where intelligence is found in the outcomes that design made with living organisms have (illuminating outside the energy grid or self-repairing materials). This invisibility that brings other species closer contact with our built environment is now considered a possibility to mitigate the negative impacts of human settlement. The issue in using living material is that it needs much more investigation on maintenance. Living beings have life spam, but they are susceptible to illness and more sensitive to environmental changes, not to mention ethical issues related to genetics and synthetic biology. Nevertheless, the

\footnotetext{
${ }^{5}$ Quorum sensing (QS) is a process of cell-to-cell communication that bacteria use to orchestrate collective behaviors in response to changes in cell population density and species composition of the community (Duddy and Basslerid 2021).
} 

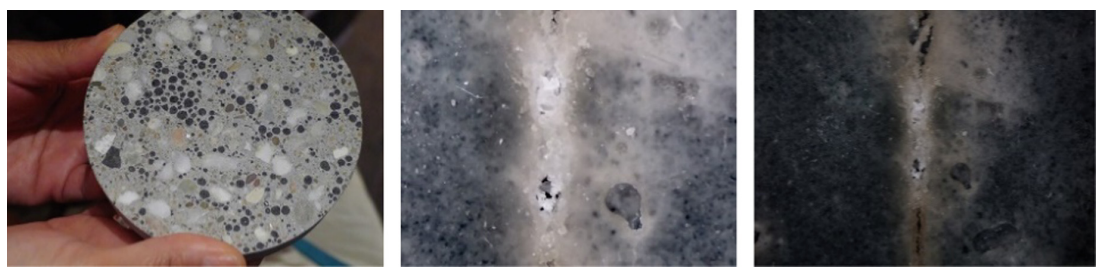

Fig. 5. Left: The bacteria and its food source, calcium lactate, are packed into tiny capsules that dissolve when water enters the concrete cracks. Once released, the bacteria consume the calcium lactate, creating limestone, filling in the gaps. Centre: bio-concrete healing process. Right: Bio-concrete healed (Greg Beach 2018)

possibility of inserting living bacteria into the material is creating a different relationship with other species. Bacterias are no longer feared and disposed of, as Marco Poletto mentioned, but they are also part of daily spaces and contributing to more sustainable solutions (Fig. 6).
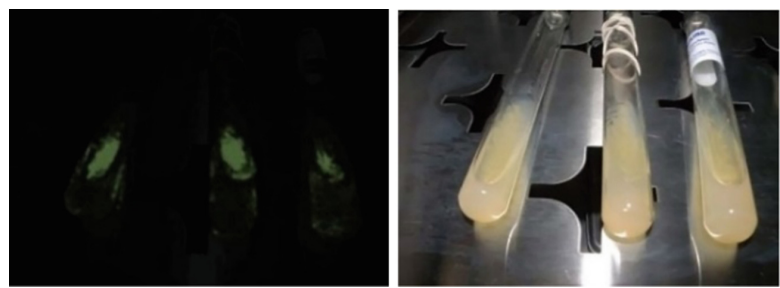

Fig. 6. Vibrio Fischeri tubes (González, Keller and Joachim no date)

\section{Conclusions}

Since the beginning of the nineteenth century, the great discoveries made in biology opened new paths for other disciplines. Architecture has been referring to the natural laws as inspiration as well as a benchmark for performance. With the advance of genetics and technologies, new research fields have been opened for architects and designers. Through technology, projects can refer to natural laws and use biomimetics as a problem-solving framework.

However, the endless search for anthropocentric problems leads us to nonanthropocentric paths. Our curiosity for the living world reached a point that thinking of 'living machines and buildings' is no longer conceptual. The projects presented in this paper illustrate growing interest in adding living complexity to architecture to reduce the stress that the Anthropocene era has caused to the planet; and, consequently, create new relationships with other living beings that share the urban space.

Merging biological elements with architecture can be thought of in multiple scales, methods with the assistance of many different technologies. Although the application of bio-design is ample, nature, as complex and compelling as it is, has its downside as 
biological processes may take a long time, whereas our development pace is incredibly fast. Traditional techniques follow the fast pace of construction and manufacturing; however, the consequences of human activities are growing in speed, forcing us to think of alternative solutions to adapt to the changing environment. Architects are experiencing a critical time to consider nonstandard solutions for climate change and sustainability as the possibilities are infinite.

\section{References}

Aldinger, I.L.: Frei Otto: heritage and prospect. Int. J. Space Struct. 31(1), 3-8 (2016). https://doi. org/10.1177/0266351116649079

Burkhardt, B.: Natural structures - the research of Frei Otto in natural sciences. Int. J. Space Struct. 31(1), 9-15 (2016). https://doi.org/10.1177/0266351116642060

Cities - United Nations Sustainable Development (2021) United Nations Sustainable Development. https://www.un.org/sustainabledevelopment/cities/. Accessed on 29 March 2021

Colmo, C., Ayres, P.: 3d Printed Bio-hybrid Structures Investigating the architectural potentials of mycoremediation. eCAADe 38(1), 575-582 (2020)

Duddy, O.P., Basslerid, B.L.: Quorum sensing across bacterial and viral domains (2021). https:// doi.org/10.1371/journal.ppat.1009074

Frederick, C.: History of ecological sciences, part 52: symbiosis studies. Bull. Ecol. Soc. Am. 96(1), 80-139 (2015). https://doi.org/10.1890/0012-9623-96.1.80

González, E., Keller, E., Joachim, M.: Swarm Intelligence in micro-organisms populations (no date)

Gough, P., et al.: The Nature of Biodesigned Systems: Directions for HCI (2020). https://doi.org/ $10.1145 / 3393914.3395908$

Greg, B.: Jonkers and bioconcrete, Inhabitat (2018). https://inhabitat.com/new-concrete-can-rep air-its-own-cracks-with-bacteria/bioconcrete-disk/. Accessed on 27 April 2021

Guallart, V.: From digital cities to biocities: harnessing the power of the digital revolution to reinvent the urban ecology model. Archit. Des. 90(3), 72-75 (2020). https://doi.org/10.1002/ ad. 2571

Heinrich, M.K., et al.: Constructing living buildings: a review of relevant technologies for a novel application of biohybrid robotics (2019). https://doi.org/10.1098/rsif.2019.0238

Joachim, M., Gervasi, N.: Effected butterflies. In: Informality through Sustainability: Urban Informality Now. Routledge (2020). https://books.google.com.au/books?hl=pt-BR\&lr=\&id= LucLEAAAQBAJ\&oi=fnd\&pg=PT151\&dq=Mitchell+Joachim+scholar+article\&ots=Z8p_ PsVYw8\&sig=MaEfR_wkFa713X8-11QNmGSHhbU\#v=onepage\&q\&f=false

Marcos, C.: TAB 2017 Symposium: Biointegrated Design (2017). https://www.youtube.com/ watch?v=jxsVG4qGUkE. Accessed on 14 April 2021

Mark, P.: Bioconcrete presages new wave inenvironmentally friendly construction.. Nat. Biotechnol. 38(7), 777-777 (2020). https://doi.org/10.1038/s41587-020-0608-y

Melkozernov, A.N., Sorensen, V.: What drives bio-art in the twenty-first century? Sources of innovations and cultural implications in bio-art/biodesign and biotechnology. AI Soc. 1-9 (2020). https://doi.org/10.1007/s00146-020-00940-0

Myers, W.: Bio Design: Nature Science Creativity - Revised and Expanded Edition, 2nd edn. THAMES \& HUDSON, London (2018)

Pacheco Torgal, F., Labrincha, J.A., Diamanti, M.V., Yu, C.-P., Lee, H.K. (eds.): Biotechnologies and Biomimetics for Civil Engineering. Springer, Cham (2015). https://doi.org/10.1007/9783-319-09287-4 
Pasquero, C., Poletto, M.: Bio-digital aesthetics as value system of post-anthropocene architecture. Int. J. Archit. Comput. 18(2), 120-140 (2020). https://doi.org/10.1177/1478077120922941

Pataranutaporn, P., et al.: Living Bits: opportunities and challenges for integrating living microorganisms in human-computer interaction. ACM Int. Conf. Proc. Ser. 10(1145/3384657), 3384783 (2020)

Poletto, C.P.M.: BioTechHUT - EcoLogicStudio, 10 June 2017. http://www.ecologicstudio.com/ v2/project.php?idcat=3\&idsubcat=71\&idproj=162. Accessed on 15 April 2021

Poletto, M.: Urban Microbiology is the Key to Building the Future of our Cities, Uncommon Cities TEDxBucharest (2018). https://www.youtube.com/watch?v=azD7YrIBUsQ. Accessed on 13 April 2021

Primrose, S.B.: Biomimetics - Nature Inspired Design and innovation. 1st edn, 16/06/2020. Edited by W. Blackwell. Wiley (2020). http://marefateadyan.nashriyat.ir/node/150

Rigobello, A.: From Mimicry to Coupling: Some Differences, Challenges and Opportunities of Bio-Hybrids. Denmark, Copenhagen (2019)

Sachs, J.D.: The Age of Sustainable Development. Columbia University Press, New York, Chichester, West Sussex (2015)

Šijaković, M., Perić, A.: Symbiotic architecture: redefinition of recycling design principles. Front. Arch. Res. 7(1), 67-79 (2018). https://doi.org/10.1016/j.foar.2017.12.002

Wuebbles, D.J., et al.: Executive Summary. Climate Science Special Report: Fourth National Climate Assessment, vol. I. Washington, DC. (2017). https://doi.org/10.7930/J0DJ5CTG

Zexin, S., Mei, H.: Robotic Form-Finding and Construction Based on the Architectural Projection Logic. IOP Conf. Ser.: Materials Sci. Eng. 216(1), 012058 (2017). https://doi.org/10.1088/ $1757-899 \mathrm{X} / 216 / 1 / 012058$

Open Access This chapter is licensed under the terms of the Creative Commons Attribution 4.0 International License (http://creativecommons.org/licenses/by/4.0/), which permits use, sharing, adaptation, distribution and reproduction in any medium or format, as long as you give appropriate credit to the original author(s) and the source, provide a link to the Creative Commons license and indicate if changes were made.

The images or other third party material in this chapter are included in the chapter's Creative Commons license, unless indicated otherwise in a credit line to the material. If material is not included in the chapter's Creative Commons license and your intended use is not permitted by statutory regulation or exceeds the permitted use, you will need to obtain permission directly from the copyright holder.

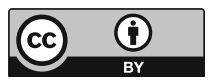

